\title{
Practicality of Tricone Bit Wear Condition Assessment
}

\author{
Hamed Rafezi (D) and Ferri Hassani \\ Department of Mining and Materials Engineering, McGill University, Montreal, QC H3A 2A7, Canada \\ ${ }^{*}$ Corresponding author: hamed.rafezi@mail.mcgill.ca
}

(Received 25 June 2020; Revised 20 July 2020; Accepted 11 August 2020)

\begin{abstract}
:
A practical bit condition monitoring system is a necessary component of autonomous drilling. Tricone bits are widely used in blasthole drilling in mining. Bits experience a variety of wear mechanisms during the operation and rolling element failure is the dominant catastrophic failure mode of tricone bits. Bit lifetime and performance significantly vary based on the working condition and the critical components of the bit i.e. rolling elements, are invisible to the direct condition monitoring systems. At McGill University, extensive research work is conducted to develop an indirect bit condition monitoring and failure prediction approach relying on the vibration signals and the technology is currently patent pending. This article presents realworld experimental evidence to show the unreliability of conservative bit changing strategy based on the bit operation life or drop in the rate of penetration (ROP) and ineffectiveness of direct wear monitoring techniques to cover the dominant failure mode.

Objective: To demonstrate the unreliability of tricone bit replacement relying on bit operation life or ROP measurement and ineffectiveness of vision-based monitoring techniques for autonomous drilling.
\end{abstract}

Keywords: Mining; Drilling; Tricone Bit; Wear Condition Monitoring; Failure Prediction

\section{Introduction}

Blasthole drilling is a preliminary step in surface mining, therefore, delays caused by bit failure could impose significant losses on the production. Tricone bit design is relatively complex (Figure 1). Cones are connected to the bit body by bearings elements. Progressive bit wear results in failure of rolling elements which is known as the dominant catastrophic failure of tricone bits and usually happens as locked or detached cones. Some research works are conducted on wear detection of tricone bits employing a variety of techniques including drilling performance measurement, study of load distribution, vibration analysis and image processing approaches (Cooper, 2002; Ghosh et al., 2016; Naganawa, 2012; Rafezi \& Hassani, 2017; 2018; Saeidi et al., 2014; Sheppard \& Lesage, 1988). This article discusses the effectiveness of ROP monitoring and image processing methods for the purpose of tricone wear monitoring based on realworld drilling data and feasibility restrictions.

\section{Method}

Blasthole drill rigs were instrumented with data acquisition units and accelerometers in two mines in Canada for measurement while drilling (MWD). Drilling vibration, control signals as well as the ROP were recorded during the complete lifecycle of tricone bits. For data labeling, bit wear condition was manually inspected, recorded, and digital images were acquired while operating in various geological formations.

\footnotetext{
(C) The Author(s), 2020. Published by Cambridge University Press. This is an Open Access article, distributed under the terms of the Creative Commons Attribution licence (http://creativecommons.org/licenses/by/4.0/), which permits unrestricted re-use, distribution, and reproduction in any medium, provided the original work is properly cited.
} 


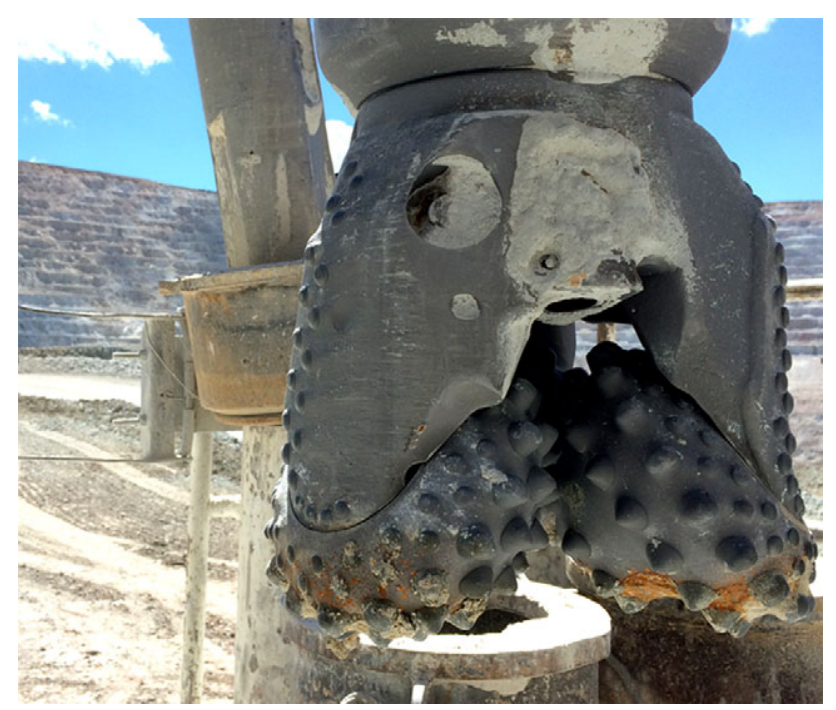

Figure 1. Tricone bit installed on the rig.

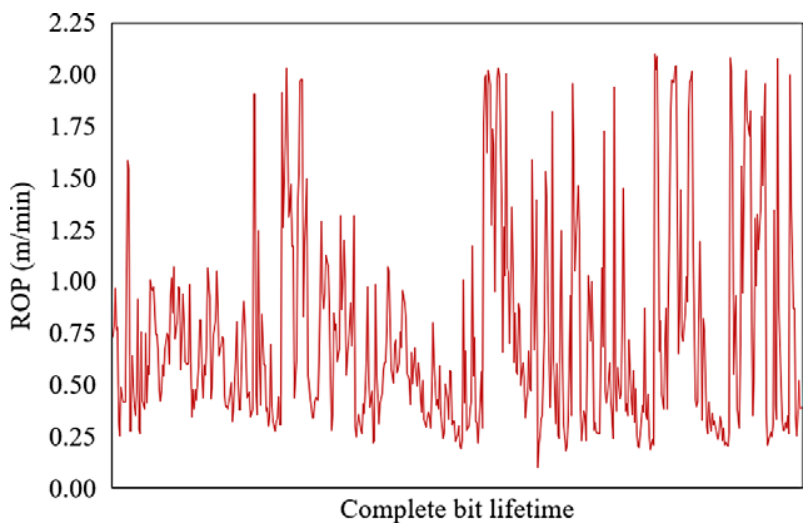

Figure 2. The rate of penetration (ROP) trend during the complete lifecycle of a bit.

\section{Results}

In this study capability of ROP assessment and imaging approaches for tricone bit wear monitoring and failure prediction were investigated. The ROP trend during the bit lifecycle, starting from a brand new bit until the bit is worn out and replaced, has a fluctuating trend (Figure 2). Consequently, as the bits become worn out, a decremental trend in the ROP is not necessarily identified in a dynamic subsurface condition. Direct assessment of bit condition through digital imaging provides an insight into the shape of the bit and the missing or broken teeth are detectable using this approach.

\section{Discussion}

It was observed that the ROP trend is significantly influenced by geological variations and as presented in the table, the lifetime of tricone bits can significantly vary (in terms of hours of operation and length of drilling) depending on the working condition for the identical bit brand, model, and diameter in the same mine site. For the bits listed in the table, the bit lives are ranging from $21.8 \mathrm{hrs}$. to $68 \mathrm{hrs}$. and from $746.1 \mathrm{~m}$ to $2805.4 \mathrm{~m}$. On the other hand, processing of digital images for condition monitoring of tricone bits has 
Table 1. Operation life of four tricone bits in one mine site

\begin{tabular}{lcccc}
\hline Tricone bit \# & Diameter & Total hours & Total meters & Average ROP $(\mathrm{m} / \mathrm{min})$ \\
\hline 1 & $105 / 8^{\prime \prime}$ & 21.8 & 746.1 & 0.570 \\
\hline 2 & $105 / 8 ”$ & 56 & 1840.7 & 0.548 \\
\hline 3 & $105 / 8 ”$ & 47.7 & 1726.2 & 0.603 \\
\hline 4 & $105 / 8^{\prime \prime}$ & 68 & 2805.4 & 0.688 \\
\hline
\end{tabular}

some essential drawbacks; infeasibility of real-time monitoring while drilling down the hole and inability to assess the bearings condition which leads to the dominant failure mode of tricone bits.

\section{Conclusions}

The effectiveness of ROP monitoring and vision-based assessments for automated tricone bit condition monitoring was investigated in fieldworks. It is concluded that the ROP is mainly determined by geological condition and extraction of bit wear status from ROP trend requires a precise knowledge subsurface condition. Analysis of tricone bit wear through visual techniques, could provide an insight about the teeth wear state, however, it is not able to cover the bearings condition. In comparison, bit vibration frequency signatures reveal information about bit rolling elements condition and have the possibility of real-time measurement without interruption of the operation. Therefore, drilling vibration analysis is a promising and practical approach for tricone wear monitoring and failure perdition in industrial applications for fully autonomous drilling.

Acknowledgement. The authors would like to thank Teck Resources and ArcelorMittal companies for enabling the mine fieldworks as well as McGill University Engine centre.

Funding. This work was supported by the Natural Sciences and Engineering Research Council of Canada NSERC (CRD grant\# 461514, I2I grant\# 516232).

Conflicts of Interest Declaration. Hamed Rafezi and Ferri Hassani declare none.

Data Availability. The data are presented in the manuscript.

Related article. Tricone bit health monitoring using wavelet packet decomposed vibration signal. Rafezi, H., \& Hassani, F., https:/doi.org/10.1109/codit.2018.8394922

\section{References}

Cooper, G. (2002). Proposal for the real-time measurement of drill bit tooth wear. Geothermal Resources Council, 26, $189-192$.

Ghosh, R., Schunnesson, H., \& Kumar, U. (2016). Evaluation of operating life length of rotary tricone bits using measurement while drilling data. International Journal of Rock Mechanics Mining Sciences, 83, 41-48.

Naganawa, S. (2012). Feasibility study on roller-cone bit wear detection from axial bit vibration. Journal of Petroleum Science and Engineering, 82, 140-150.

Rafezi, H., \& Hassani, F. (2017). Drill bit wear monitoring based on vibration signal analysis. 30th International Congress on Condition Monitoring and Diagnostic Engineering Management (COMADEM), Preston, UK.

Rafezi, H., \& Hassani, F. (2018). Tricone bit health monitoring using wavelet packet decomposed vibration signal. 5th International Conference on Control, Decision and Information Technologies (CoDIT), Thessaloniki, GR.

Saeidi, O., Rostami, J., Ataei, M., \& Torabi, S. R. (2014). Use of digital image processing techniques for evaluating wear of cemented carbide bits in rotary drilling. Automation in Construction, 44, 140-151.

Sheppard, M., \& Lesage, M. (1988). The forces at the teeth of a drilling rollercone bit: Theory and experiment. Society of Petroleum Engineers (SPE) Annual Technical Conference and Exhibition, Houston, Texas, USA.

Cite this article: Rafezi H, Hassani F (2020). Practicality of Tricone Bit Wear Condition Assessment Experimental Results, 1, e35, 1-6. https://doi.org/10.1017/exp.2020.42 


\section{Peer Reviews}

\section{Reviewing editor: Prof. Guney Guven Yapici}

Ozyegin University, Mechanical Engineering, Nisantepe Mh. Orman Sk. No:34-36, Istanbul, Turkey, 34794

This article has been accepted because it is deemed to be scientifically sound, has the correct controls, has appropriate methodology and is statistically valid, and has been sent for additional statistical evaluation and met required revisions.

doi:10.1017/exp.2020.42.pr1

\section{Review 1: Practicality of Tricone Bit Wear Condition Assessment}

Reviewer: Dr. Miho Klaic

Date of review: 12 July 2020

(C) The Author(s), 2020. Published by Cambridge University Press This is an Open Access article, distributed under the terms of the Creative Commons Attribution licence (http://creativecommons.org/licenses/by/4.0/), which permits unrestricted re-use, distribution, and reproduction in any medium, provided the original work is properly cited.

Conflict of interest statement. This paper does not provide clear guidelines on how the research will proceed. The author did not give detailed instructions on how to implement (or has implemented) a tool condition monitoring system. The author introduced the term "rate of penetration (ROP)", which corresponds with feed rate ( $\mathrm{m} / \mathrm{min}$ ) in cutting theory. I didn't see which type of signal (in the tool wear monitoring system) will be compared to feed rate to get information about tool wear. What about the mechanical properties of the rocks which is used in experimental? Does it affect to the wear rate on the cutting edge of the tools...?

Comments to the Author: This paper does not provide clear guidelines on how the research will proceed.

The author did not give detailed instructions on how to implement (or has implemented) a tool condition monitoring system.

The author introduced the term "rate of penetration (ROP)", which corresponds with feed rate $(\mathrm{m} / \mathrm{min})$ in cutting theory. I didn't see which type of signal (in the tool wear monitoring system) will be compared to feed rate to get information about tool wear.

What about the mechanical properties of the rocks which is used in experimental? Does it affect to the wear rate on the cutting edge of the tools...?

\section{Score Card}

Presentation 
Does the abstract correctly embody the content of the article? (25\%)

Does the introduction give appropriate context? (25\%)

Is the objective of the experiment clearly defined? (25\%)

Analysis

Does the discussion adequately interpret the results presented? (40\%)

Is the conclusion consistent with the results and discussion? (40\%)

Are the limitations of the experiment as well as the contributions of the experiment clearly outlined? $(20 \%)$ 


\section{Review 2: Practicality of Tricone Bit Wear Condition Assessment}

\section{Reviewer: Prof. Rahman Torabi iD}

Shahrood University of Technology, Mining, Petroleum and Geophysics, 7-Tir Sq. Shahrood, Iran, Shahrood, Semnan, Iran (the Islamic Republic of), 3619995161

Date of review: 16 July 2020

(C) The Author(s), 2020. Published by Cambridge University Press This is an Open Access article, distributed under the terms of the Creative Commons Attribution licence (http://creativecommons.org/licenses/by/4.0/), which permits unrestricted re-use, distribution, and reproduction in any medium, provided the original work is properly cited.

Conflict of interest statement. Hereby it is declared that I have no conflict of interest in relation to this manuscript. Dr. Seyed Rahman Torabi

Comments to the Author: Dear Author,

Outlining the deficiencies and shortcomings of the existing tricone bit wear monitoring methods including operation life procedures, ROP based techniques, and image processing technologies in this article is useful and provides initiatives for more research in finding new methods such as the one, mentioned in the article. However, in my opinion, as it appears that the main aim of this research is to provide a background to introduce your new effort underway at your university in the area of vibration signals analysis method, presumably, it could be a good idea to very concisely list the main features of this new method. Particularly, since this new approach is highlighted in the abstract, the reader is quite eager to receive minimum information about it somewhere in this article.

\section{Score Card}

Presentation

Is the article written in clear and proper English? (30\%)

Is the data presented in the most useful manner? (40\%)

Does the paper cite relevant and related articles appropriately? (30\%)

\section{Context}

\section{5}

Does the title suitably represent the article? (25\%)

Does the abstract correctly embody the content of the article? (25\%)

Does the introduction give appropriate context? (25\%)

Is the objective of the experiment clearly defined? (25\%)

Analysis

Is the conclusion consistent with the results and discussion? (40\%)

Are the limitations of the experiment as well as the contributions of the experiment clearly outlined? (20\%) 